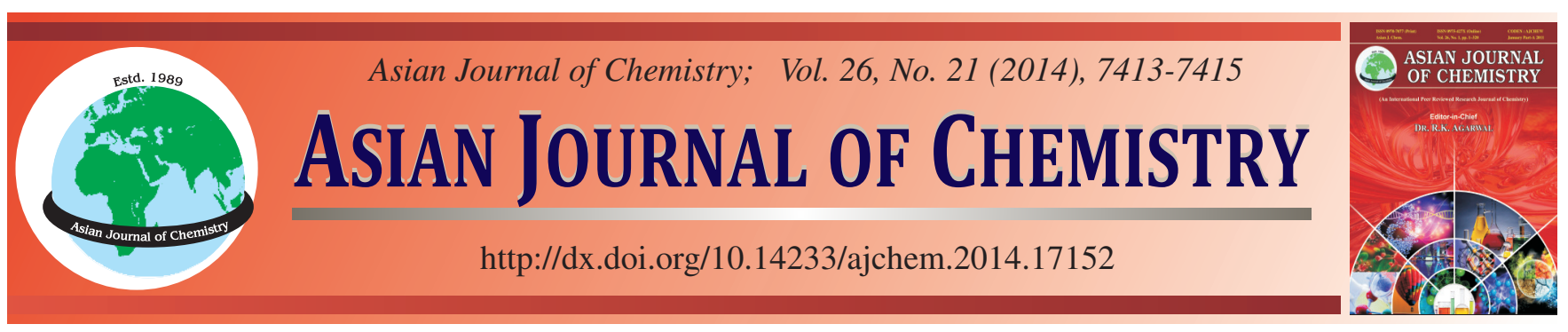

\title{
Phase Transfer Catalyzed Synthesis and Biological Activity of Thiourea Derivatives Containing 1,2,3-Thiadiazole Moiety
}

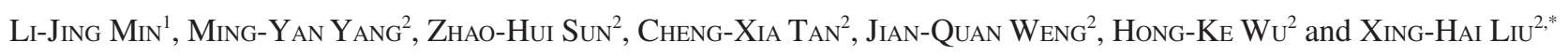

${ }^{1}$ College of Life Sciences, Huzhou Teachers College, Huzhou 313000, Zhejiang, P.R. China

${ }^{2}$ College of Chemical Engineering and Materials Science, Zhejiang University of Technology, Hangzhou 310014, Zhejiang, P.R. China

*Corresponding author: E-mail: xhliu@ zjut.edu.cn

Received: 31 January 2014;

Accepted: 18 February 2014;

Published online: 30 September 2014;

AJC-16150

\begin{abstract}
A series of $N$-(substituted-phenyl)- $N$-(4-methyl-1,2,3-thiadiazole-5-yl)-thiourea (7a-7e) were synthesized and characterized. The chemical structures of all the compounds were confirmed by ${ }^{1} \mathrm{H}$ NMR, MS and elemental analysis. All the compounds were investigated for fungicidal activity and plant growth regulatory activity. The bioassay results indicated that some of these compound exhibit moderate fungicidal activities.
\end{abstract}

Keywords: 1,2,3-Thiadiazole, Thiourea, Synthesis, Fungicidal activity, Plant growth regulatory activity.

\section{INTRODUCTION}

Heterocyclic compounds, especially nitro containing heterocycles, received considerable attention due to their pharmacological and pesticidal importance ${ }^{1-4} \cdot 1,2,3$-Thiadiazole exhibited diversity activities, some derivatives had been developed commercial pesticide, such as plant inducer thiadinal ${ }^{5}$, $\mathrm{BTH}^{6}$, (Fig. 1). So 1,2,3-thiadiazoles pesticide may become one of the focuses in the research and development of agrochemicals $^{7}$.

On the other hand, thiourea and its derivatives, especially acyl-thiourea compounds, had many functions in agriculture ${ }^{8}$, medicine ${ }^{9}$, analytical chemistry ${ }^{10}$ and inorganic synthesis ${ }^{11}$. For example, $N, N$-disubstituted thiourea exhibited a remarkable biological activities. Some thiourea was synthesized containing 1,2,3-thiadiazole, which exhibit some plant growth regulate activities (Fig. 1) ${ }^{12}$.<smiles>Cc1ccc(NC(=O)c2snnc2C)cc1Cl</smiles>

thiadinal<smiles>CS(=O)(=O)c1cccc2nnsc12</smiles>

$\mathrm{BTH}$<smiles>[R]N([R])C(=S)NC(=O)c1csnn1</smiles>

Fig. 1. Commercial pesticide containing 1,2,3-thiadiazole
Phase transfer catalysis (PTC) is a powerful technique accomplishing a variety of reactions under mild conditions and efficient way. This technique has been widely recognized as an efficient synthetic tool and attracted much attention ${ }^{13,14}$.

In view of these facts, herein we report the synthesis of $N$-(substituted-phenyl)- $N$ '-(4-methyl-1,2,3-thiadiazole-5-yl)thiourea under the condition of solid-liquid phase transfer catalysis using polyethylene glycol-600 (PEG-600) as the catalyst (Fig. 2) and their biological activities were investigated.

\section{EXPERIMENTAL}

Melting points were determined using a X-4 melting apparatus and were uncorrected. ${ }^{1} \mathrm{H}$ NMR spectra were measured on a Bruker AC-P300 instrument (300 MHz) using tetramethylsilane as an internal standard and DMSO- $d_{6}$ as solvent. Mass spectra were recorded on a Thermo Finnigan LCQ Advantage LC/mass detector instrument. Elemental analyses were performed on a Yanaco MT-3CHN elemental analyzer.

General procedure: The title compounds were synthesized according to the route shown in Fig. 2 and the yields were not optimized.

4-Methyl-1,2,3-thiadiazole-5-carbonyl chloride: 4Methyl-1,2,3-thiadiazole-5-carboxylic acid was obtained through ethyl 3-oxobutanoate and ethyl hydrazinecarboxylate according the Hurd-Mori reaction. Then the $\mathrm{SOCl}_{2}$ was added dropwise into 4-methyl-1,2,3-thiadiazole-5-carboxylic acid and refluxed about $2 \mathrm{~h}$, the acyl chloride was obtained after evaporate the residue $\mathrm{SOCl}_{2}$. The ethyl 4-methyl-1,2,3- 
<smiles>CCOC(=O)OCCOC(=O)NN</smiles>

1<smiles>CCOC(=O)C/C(C)=N\NC(=O)OCC</smiles>

2<smiles>CCOC(=O)c1snnc1C</smiles>

3<smiles>Cc1nnsc1C(=O)O</smiles>

4<smiles></smiles>

5

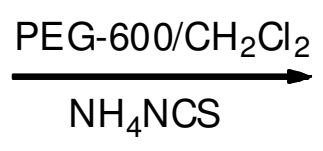<smiles>Cc1nnsc1C(=O)NS(C)(=O)=O</smiles>

6<smiles>Cc1nnsc1C(=O)NC(=S)NC1=CC=IC=C1</smiles>

7

Fig. 2. Synthetic route of title compounds

thiadiazole-5-carboxylate were stirred in the solution of $\mathrm{HCl}$ at room temperature. Then 4-methyl-1,2,3-thiadiazole-5carbonxylic acid was reacted with $\mathrm{SOCl}_{2}$ to give 4-methyl1,2,3-thiadiazole-5-carbonyl chloride.

$N$-(Substituted-phenyl)- $N$ '-(4-methyl-1,2,3-thiadiazole5-yl)-thiourea: Powdered ammonium thiocyanate (1.14 g, 15 mmol), 4-methyl-1,2,3-thiadiazole-5-carbonyl chloride (1.62 g, 10 mmol), PEG-600 (0.18 g, $3 \%$ with respect to ammonium thiocyanate) and methylene dichloride $(25 \mathrm{~mL})$ were placed in a dried round-bottomed flask containing a magnetic stirrer bar and stirred at room temperature for $1 \mathrm{~h}$. Then substituted aniline $(4.5 \mathrm{mmol})$ in methylene dichloride $(10 \mathrm{~mL})$ was added dropwise over $0.5 \mathrm{~h}$ and the mixture was stirred for $1 \mathrm{~h}$. The corresponding $N$-(substituted-phenyl)- $N$ '-(4-methyl-1,2,3thiadiazole-5-yl)-thiourea (7a-e) precipitated immediately. The product was filtered, washed with water to remove inorganic salts, dried and recrystallized from DMF-EtOH- $\mathrm{H}_{2} \mathrm{O}$ to give the title compounds $7 \mathbf{a}-\mathbf{e}$.

$N$-5-(2,5-Dichlorophenyl)- $N$ '-(4-methyl-1,2,3-thiadiazole5-yl)-thiourea (7a): Yellow solid, yield 85.9 \%, m.p. 181-183 ${ }^{\circ} \mathrm{C}$; ${ }^{1} \mathrm{H}$ NMR: 8.35 (s, 1H, NH), 8.14 (s, 1H, NH), 7.39-7.44 (m, 1H, Ph), 7.18-7.30 (m, 1H, Ph), 7.13-7.17 (m, 1H, Ph), 2.81 (s, 3H, $\mathrm{CH}_{3}$ ); ESI-MS: 346 (M-1); Anal. calcd. for $\mathrm{C}_{11} \mathrm{H}_{8} \mathrm{~N}_{4} \mathrm{OS}_{2} \mathrm{Cl}_{2}$ : C 38.05, H 2.32, N 16.13; found: C 37.88, H 2.21, N 16.32.

$N$-5-(4-Flurophenyl)- $N^{\prime}$-(4-methyl-1,2,3-thiadiazole-5yl)-thiourea (7b): Yellow solid, yield 83.8 \%, m.p. 166-168 ${ }^{\circ} \mathrm{C}$; ${ }^{1} \mathrm{H}$ NMR: 11.96 (s, 1H, NH), 10 (s, 1H, NH), 7.63-7.66 (m, 1H, Ph), 7.26-7.29 (m, 2H, Ph), 2.80 (s, 3H, CH $)$; ESIMS: 295 (M-1); Anal. calcd. for $\mathrm{C}_{11} \mathrm{H}_{9} \mathrm{~N}_{4} \mathrm{OS}_{2} \mathrm{~F}$ : C 44.58, $\mathrm{H}$ 3.06, N 18.91; found: C 44.46, H 3.13, N 18.76.

$N$-5-(3-Nitrophenyl)- $N^{\prime}$-(4-methyl-1,2,3-thiadiazole-5yl)-thiourea (7c): Yellow solid, yield 85.8\%, m.p. $115-117{ }^{\circ} \mathrm{C}$; ${ }^{1}$ H NMR: 12.20 (s, 1H, NH), 8.71 (s, 1H, NH), 8.13 (m, $J=$
$8.48 \mathrm{~Hz}, 1 \mathrm{H}, \mathrm{Ph}), 8.02(\mathrm{~d}, J=7.72 \mathrm{~Hz}, 1 \mathrm{H}, \mathrm{Ph}), 7.71(\mathrm{t}, J=$ $8.09 \mathrm{~Hz}, 1 \mathrm{H}, \mathrm{Ph}$ ), 2.82 (s, 3H, $\mathrm{CH}_{3}$ ); ESI-MS: 322 (M-1); Anal. calcd. for $\mathrm{C}_{11} \mathrm{H}_{9} \mathrm{~N}_{5} \mathrm{O}_{3} \mathrm{~S}_{2}$ : C 40.86, $\mathrm{H}$ 2.81, N 21.66; found: C 40.89, H 3.01, N 21.66.

$N$-5-(4-Methylphenyl)- $N^{\prime}$-(4-methyl-1,2,3-thiadiazole5-yl)-thiourea (7d): Yellow solid, yield $88.9 \%$, m.p. 137$138{ }^{\circ} \mathrm{C} ;{ }^{1} \mathrm{H}$ NMR: 12.10 (s, 1H, NH), 11.96 (s, 1H, NH), 7.53 (d, $J=8.30 \mathrm{~Hz}, 2 \mathrm{H}, \mathrm{Ph}), 7.22(\mathrm{~d}, J=8.30 \mathrm{~Hz}, 2 \mathrm{H}, \mathrm{Ph}), 2.80$ (s, $3 \mathrm{H}, \mathrm{CH}_{3}$ ), 2.31 (s, 3H, $\mathrm{CH}_{3}$ ); ESI-MS: 291 (M-1); Anal. calcd. for $\mathrm{C}_{1}{ }_{2} \mathrm{H}_{12} \mathrm{~N}_{4} \mathrm{OS}_{2}$ : C 49.29, H 4.14, N 19.16; found: C 49.10, H 4.56, N 19.44.

$N$-5-(4-nitrophenyl)- $N^{\prime}$-(4-methyl-1,2,3-thiadiazole-5yl)-thiourea (7e): Yellow solid, yield 87.6 \%, m.p. 175-177 ${ }^{\circ} \mathrm{C}$; ${ }^{1} \mathrm{H}$ NMR: 12.31 (bs, 2H, NH), 8.28 (d, $J=9.10 \mathrm{~Hz}, 2 \mathrm{H}$, $\mathrm{Ph}), 8.04$ (d, J = 9.10 Hz, 2H, Ph), 2.81 (s, 3H, CH 3 ); ESI-MS: 322 (M-1); Anal. calcd. for $\mathrm{C}_{11} \mathrm{H}_{9} \mathrm{~N}_{5} \mathrm{O}_{3} \mathrm{~S}_{2}$ : C 40.86, H 2.81, N 21.66; found: C 40.77, H 2.78, N 21.54.

Bioassay of fungicidal activities: The method for testing the primary biological activities was performed in an isolated culture. Under a sterile condition, $1 \mathrm{~mL}$ of sample was added to the culture plates, followed by the addition of $9 \mathrm{~mL}$ of culture medium. The final mass concentration was $50 \mu \mathrm{g} / \mathrm{mL}$. The blank assay was performed with $1 \mathrm{~mL}$ of sterile water. Circle mycelium with a diameter of $4 \mathrm{~mm}$ was cut using a drill. The culture plates were cultivated at $(24 \pm 1){ }^{\circ} \mathrm{C}$. The extended diameters of the circle mycelium were measured after $72 \mathrm{~h}$. The relative inhibition rate of the circle mycelium compared to blank assay was calculated via the following equation:

$$
\text { Relative inhibition rate }(\%)=\frac{\mathrm{d}_{\mathrm{ex}}-\mathrm{d}_{\mathrm{ex}}{ }^{\prime}}{\mathrm{d}_{\mathrm{ex}}} \times 100 \%
$$

where $d_{e x}$ is the extended diameter of the circle mycelium during the blank assay; and $\mathrm{d}_{\mathrm{ex}}{ }^{\prime}$, is the extended diameter of the circle mycelium during testing. 


\begin{tabular}{|c|c|c|c|c|c|c|}
\hline \multicolumn{7}{|c|}{$\begin{array}{c}\text { TABLE-1 } \\
\text { BIOLOGICAL ACTIVITY OF TESTED COMPOUNDS }\end{array}$} \\
\hline No. & G. zeae Petch & $\begin{array}{c}\text { Phytophthora } \\
\text { infestans (Mont.) } \\
\text { de Bary }\end{array}$ & $\begin{array}{c}\text { Botryosphaeria berengeriana } \\
\text { f. sp. piricola (Nose) koganezawa } \\
\text { et Sakuma }\end{array}$ & $\begin{array}{l}\text { Fusarium } \\
\text { oxysporum f.sp. } \\
\text { cucumerinum }\end{array}$ & $\begin{array}{l}\text { Cercospora } \\
\text { arachidicola }\end{array}$ & $\begin{array}{l}\text { Cotyledon root } \\
\text { of cucumber }\end{array}$ \\
\hline $7 \mathbf{a}$ & 13.0 & 35.3 & 22.7 & 21.5 & 8.6 & 13.2 \\
\hline $7 \mathbf{b}$ & 1 & 1 & 22.7 & 23.8 & 17.4 & 46.2 \\
\hline 7c & 21.7 & 1 & 18.2 & 27.7 & 8.6 & 13.2 \\
\hline 7d & 13.0 & 11.7 & 18.2 & 33.8 & 1 & 116.9 \\
\hline $7 e$ & 18.8 & 21.4 & 26.3 & 28.3 & 7.1 & 98.1 \\
\hline
\end{tabular}

Plant growth regulatory activity assay: After dipping into distilled water for $1 \mathrm{~h}$ at $23^{\circ} \mathrm{C}$, the cucumber seeds (Jinke, No. 4, commercial availably) were then sown into the soil with $0.7 \%$ agar on a covered porcelain enamel plate and incubated at $26{ }^{\circ} \mathrm{C}$ in a darkroom for 3 days. The same sized cotyledons were carefully selected for the subsequent biological assay. The analyte ( $3 \mathrm{mg}$ ) was resolved in $\mathrm{N}, \mathrm{N}$-dimethyl formamide $(3 \mathrm{~mL})$ and this solution was then diluted to $10 \%$ concentration with distilled water. A sample solution $(0.3 \mathrm{~mL})$ was sprayed over a $6 \mathrm{~cm}$ diametered filter paper and solvent was volatilized to dryness on air. The filter paper thus prepared was placed into a $6 \mathrm{~cm}$ diameter incubation vessel and soaked with $10 \mathrm{~cm}$ distilled water. Finally, 10 pieces of cotyledon of the same size were added into the incubation vessel. These cotyledons were incubated at $26^{\circ} \mathrm{C}$ in a darkroom for 5 days. Then the rhizogenesis numbers of every 10 pieces of hypocotyls were measured. Each sample was repeated twice. In contrast, the distilled water was used as a blank experiment. The relative ratios of cucumber cotyledon rhizogenesis were calculated according to the following formula:

$$
\text { Relative ratio }(\%)=\frac{\left(\mathrm{N}_{\mathrm{S}}-\mathrm{N}_{\mathrm{C}}\right)}{\mathrm{N}_{\mathrm{C}}} \times 100 \%
$$

where $\mathrm{N}_{\mathrm{S}}$ and $\mathrm{N}_{\mathrm{C}}$ are the numbers of cucumber cotyledon rhizogenesis of tested compound and control experiment, respectively.

\section{RESULTS AND DISCUSSION}

4-Methyl-1,2,3-thiadiazole-5-carboxylic acid was synthesized according the Hurd-Mori method. The hydrazone must be added dropwise into the $\mathrm{SOCl}_{2}$. PEG-600 was used as solid-liquid phase transfer catalyst, this is a facile and convenient method to afford the title compounds $N$-(substitutedphenyl)- $N$-(4-methyl-1,2,3-thiadiazole-5-yl)- thiourea. PEG600 can easily react with $\mathrm{NH}_{4} \mathrm{SCN}$ to form complex [PEG$\left.600-\mathrm{NH}_{4}{ }^{+}\right] \mathrm{SCN}^{-}$, which makes it possible for $\mathrm{SCN}^{-}$to readily react with 4-methyl-1,2,3-thiadiazole-5-carbonyl chloride and leads to the formation of intermediate 6 . Also the catalyst PEG600 is inexpensive, relatively nontoxic, highly stable and easily available.

Biological activities: Fungicidal activities of the title compounds against G. zeae Petch, Phytophthora infestans (Mont.) de Bary, Botryosphaeria berengeriana f. sp. piricola (Nose) koganezawa et Sakuma, Fusarium oxysporum f. sp. cucumerinum and Cercospora arachidicola. The fungicidal activities and plant growth regulatory activity of title compounds were determined. The results were shown in Table-1. As shown in Table-1, the title compound exhibit weak activity against $G$. zeae Petch., Phytophthora infestans (Mont.) de Bary, Botryosphaeria berengeriana f. sp. piricola (Nose) koganezawa et Sakuma, Fusarium oxysporum f. sp. cucumerinum and Cercospora arachidicola. Only compound $7 \mathbf{a}$ and $\mathbf{7 d}$ showed fair fungicidal activity (35.3 and $33.8 \%$ ) against Botryosphaeria berengeriana f. sp. piricola (Nose) koganezawa et Sakuma and Fusarium oxysporum f.sp. cucumerinum, respectively.

The cotyledon root of cucumber activity of title compounds was determined. Surprisingly, as listed in Table-1, all the testing compounds showed low activity on the roots cotyledon of cucumber. The compound $\mathbf{7 d}$ and $\mathbf{7 e}$ showed excellent activity (116.9 and 98.1).

\section{ACKNOWLEDGEMENTS}

This work was funded by National Natural Science Foundation of China (No. 21002090), The Key Innovation Team of Science and Technology in Zhejiang Province (2010R50018-06) and the National Key Technologies R\&D Program (2011BAE06B03-01).

\section{REFERENCES}

1. S. Nanjunda Swamy, Basappa, G. Sarala, B.S. Priya, S.L. Gaonkar, J. Shashidhara Prasad and K.S. Rangappa, Bioorg. Med. Chem. Lett., 16, 999 (2006)

2. F.Q. He, X.H. Liu, B.L. Wang and Z.M. Li, Heteroatom Chem., 19, 21 (2008).

3. X.D. Yang, Heterocycl. Commun., 13, 387 (2007).

4. S. Yang, Z. Li, L. Jin, B. Song, G. Liu, J. Chen, Z. Chen, D. Hu, W. Xue and R. Xu, Bioorg. Med. Chem. Lett., 17, 2193 (2007).

5. K. Tsubata, O. Sanpei, K. Takagi, K. Umetani, T. Uchikurohane and S. Tajima, WO 9923084 (1999); Chem. Abstr., 130, 311799 (1999).

6. W. Kunz, R. Schurter and T. Maetzke, Pestic. Sci., 50, 275 (1997).

7. C.B. Ziegler Jr., W.V. Curran, N.A. Kuck, S.M. Harris and Y. Lin, J. Heterocycl. Chem., 26, 1141 (1989).

8. X.Q. He, W.M. Tang, B.A. Song, D.Y. Hu, L.L. Pang, W.J. Sang, S. Yang and L.H. Jin, Chin. J. Org. Chem., 24, 1284 (2004).

9. S.A.F. Rostom, Bioorg. Med. Chem., 14, 6475 (2006).

10. A. Lukomska and J. Sobkowski, J. Electroanal. Chem., 592, 68 (2006).

11. G. Binzet, H. Arslan, U. Flörke, N. Külcü and N. Duran, J. Coord. Chem., 59, 1395 (2006).

12. Y.H. Dong and Z.X. Si, Chin. J. Appl. Chem., 12, 62 (1995).

13. P. Sharma, A. Kumar and P. Pandey, Indian J. Chem., 45B, 2077 (2006).

14. T.B. Wei, H. Wang, Q. Lin and Y.M. Zhang, Chin. J. Org. Chem., 25, 1565 (2005). 